\title{
Layered double hydroxides as fillers in poly(l-lactide) nanocomposites, obtained by in situ bulk polymerization
}

\author{
Telma Nogueira1*, Núria Gonçalves ${ }^{1}$, Rodrigo Botan ${ }^{1}$, Fernando Wypych ${ }^{2}$ and Liliane Lona ${ }^{1}$ \\ 'Laboratory of Analysis, Simulation and Synthesis of Chemical Process - LASSPQ, \\ Department of Materials Engineering and Bioprocesses, School of Chemical Engineering, \\ Universidade Estadual de Campinas - UNICAMP, Campinas, SP, Brazil \\ ${ }^{2}$ Advanced Materials Chemistry Laboratory, Chemistry Department, Universidade Federal \\ do Paraná - UFPR, Curitiba, PR, Brazil \\ *telma.nogueira@gmail.com
}

\begin{abstract}
In this study in situ bulk polymerization of L-lactide filled with layered double hydroxides (LDH) was investigated. Four different LDHs intercalated with two different organic anions (salicylate and sebacate) were synthesized and characterized. After characterization, these synthetic layered compounds were used as fillers in poly(L-lactide) (PLLA) nanocomposites with two different fillers's loadings (1 wt $\%$ and $2 \mathrm{wt} \%$ ). PLLA and PLLA nanocomposites were evaluated by X-ray diffraction (XRD), Fourier transform infrared spectroscopy (FTIR), ultraviolet and visible spectroscopy, thermogravimetric analysis (TGA), dynamical mechanical analysis (DMA), flexural testing and differential scanning calorimetry (DSC). The results demonstrated that, compared to PLLA, the nanocomposite containing $1 \mathrm{wt} \%$ of $\mathrm{Zn} / \mathrm{Al}$ salicylate transmitted less UVA and UVB light, while keeping a similar transparency in the visible region. Thermogravimetric analysis revealed that the nanocomposite with $1 \mathrm{wt} \%$ of $\mathrm{Zn} / \mathrm{Al}$ salicylate exhibited the highest thermal stability. In general the flexural and dynamical mechanical properties were reduced in compassion to neat PLLA. DSC results, demonstrated that, compared to PLLA, all the nanocomposites exhibited lower glass transition temperature and melting temperature values.
\end{abstract}

Keywords: layered double hydroxide, polylactide, polymeric nanocomposites, in-situ polymerization.

\section{Introduction}

Nowadays, the reduction of the environmental impact caused by non-biodegradable polymers is a growing interest, especially when they are applied in the production of disposable items, such as packaging. For such applications nontoxic, biodegradable and derived from a renewable source polymers have been studied. Among the polymers in this category, poly(lactic acid) (PLA) has been identified as a good candidate to partially substitute petroleum-derived polymer such as polypropylene, polystyrene, or polyethylene(terephthalate) in some uses ${ }^{[1]}$. Typical PLA medical applications include suture materials, drug delivery systems and oral and orthopaedic internal fixation devices. PLA is one of the commercially available biodegradable polymers from the family of aliphatic polyesters, which are produced from lactic acid, a monomer that can be synthesized from many renewable resourses such as corn and sugar beets. Althouth it has good mechanical properties such as high strength, thermoplasticity, transparency, and fabricability, its applications are limited because of its brittleness and nonflexibility ${ }^{[2]}$.

In order to try to improve mechanical and thermal polymer properties and/or add new functional properties, there is a growing interest in the development of polymeric nanocomposites filled with layered compounds.

There is a wide variety of both synthetic and natural crystalline fillers that are able, under specific conditions, to intercalate a polymer ${ }^{[3]}$.
Layered compounds of natural or synthetic origin are a special class of compounds in which the crystals are built by stacking of two dimensional units (the layers), which are bound to each other through weak forces. Depending on the genesis, conditions and chemical composition, the empty crystallographic sites between the layers can be occupied by anhydrous or solvated cationic, anionic, or neutral species, producing the intercalation compounds $s^{[4]}$.

One simple classification of the layered compounds can be made according to the charge of the layers: i) Compounds with neutral layers such as graphite, layered single hydroxides like $\mathrm{Mg}(\mathrm{OH})_{2}$ and $\mathrm{Al}(\mathrm{OH})_{3}$; different transition metal chalcogenides like $2 \mathrm{H}-\mathrm{MoS}_{2}, 1 \mathrm{~T}-\mathrm{TiS}_{2}, \mathrm{~V}_{2} \mathrm{O}_{5}, \mathrm{MoO}_{3}$; ii) Compounds with positively charged layers, which are compensed by the intercalation of hydrated anions as can be observed in layered double hydroxides and layered hydroxide salts; iii) Compounds, which have negatively charged layers as transition metal dichalcogenides after chemical or electrochemical reduction or some 2:1 clay minerals ${ }^{[4]}$.

Cationic exchanger clays from 2:1 groups, like montmorillonite, have been extensively investigated as polymeric filler. Polymer nanocomposites filled with anionic exchangers having Brucite-like structure, layered double hydroxides (LDH), have attracted considerable technological and scientific interest.

In the Brucite structure, when part of divalent cations is isomorphically replaced by trivalent cations, positive 
charges are generated. In order to compensate this charge excess and stabilize the structure, exchangeable hydrated anions are inserted in the interlayer spacing, generating the LDHs. The LDHs can be represented by the general formula: $\left[\mathrm{M}^{2+}{ }_{1-\mathrm{x}} \mathrm{M}^{3+}{ }_{\mathrm{x}}(\mathrm{OH})_{2}\right]^{\mathrm{x}}\left(\mathrm{A}^{\mathrm{n}-}\right)_{\mathrm{x} / \mathrm{n}} \cdot \mathrm{mH}_{2} \mathrm{O}$, where $\mathrm{M}^{2+}$ and $\mathrm{M}^{3+}$ are the divalent and trivalent cations (a large number of cations combinations can be employed), $\mathrm{A}^{\mathrm{n}-}$ is the interlayer anion with $\mathrm{n}^{-}$charge.

Few groups investigated the properties of the nanocomposites of PLLA filled with $\mathrm{LDHs}^{[1,2,5-12]}$, but in these researches the produced LDHs were composed by only two pairs of divalent-trivalent cations: $\mathrm{Mg} / \mathrm{Al}{ }^{[1-2,5-7,9-12]}$ and $\mathrm{Zn} / \mathrm{Al}^{[8,11]}$. Besides, nanocomposites of PLLA filled with LDH intercalated by the anions evaluated in the present study (salicylate and sebacate) were not found.

The objective of the present study was to investigate the in situ bulk polymerization of L-Lactide in the presence of LDHs intercalated by the anions salicylate or sebacate. PLLA nanocomposites were prepared by in situ intercalative ring opening polymerization of L-lactide. LDHs containing different compositions $\left(\mathrm{Zn} / \mathrm{Al}\right.$ and $\mathrm{Zn} / \mathrm{Cr}$ ) and $\mathrm{M}^{+2} / \mathrm{M}^{+3}$ molar ratios $(2: 1)$ were synthesized by co-precipitation method. Mechanical, thermal and optical properties of PLLA and PLLA nanocomposites were evaluated. Although some mechanical and thermal properties of PLLA nanocomposites reinforced by LDHs have already been investigated ${ }^{[5,8]}$, melt blending or solution casting routes were used to prepare the nanocomposites, besides flexural properties were not evaluated. As far as the authors know, studies considering nanocomposites of PLLA filled with LHDs containing $\mathrm{Zn} / \mathrm{Cr}$ as divalent/trivalent cations were not found.

\section{Materials and Methods}

\subsection{Materials}

(3 S)-cis-3,6-dimethyl-1,4-dioxane-2,5-dione (lactide) (Sigma Aldrich, 98\%) and tin (II) 2-ethylhexanoate (stannous octoate) (Sigma Aldrich, 95\%) were used to produce PLLA and PLLA nanocomposites. The chemical used to prepare the LDHs like sodium hydroxide, zinc chloride, aluminum chloride, salicylic acid, sebacic acid (Ecibra), chromium chloride hexahydrate (Vetec) were of analytical grade and used as received.

\subsection{Methods}

\subsubsection{Preparation of layered double hydroxides}

Layered double hydroxides were produced by co-precipitation method. This method consists in a controlled precipitation by addition of an alkaline solution ${ }^{[13]}$. In order to avoid the presence of carbonate anions between the LDH layers, this synthesis was performed under nitrogen atmosphere. After weighing the required amounts of selected chlorides, intercalating anion precursors and sodium hydroxide, they were dissolved in deionized and decarbonated water. The intercalating anion precursor solutions were placed in the reactor. The mixed salts and sodium hydroxide solutions were simultaneously and dropwise added to the reactor to maintain the $\mathrm{pH}$ near 10 . The final mixture was left to react at a $\mathrm{pH}$ close to 8 for 12 hours, under dynamic flow of nitrogen. The mixture was centrifuged at $4000 \mathrm{rpm}$ for
12 minutes, the supernatant was discarded and the precipitate was washed with deionized water, these processes were repeated for five times. The solids were dried in an oven for seven days at $45^{\circ} \mathrm{C}$.

$\mathrm{Zn} / \mathrm{Al}$ 2:1 and $\mathrm{Zn} / \mathrm{Cr}$ 2:1 LDH were synthesized, where the intercalated anions were salicylate and sebacate. These anionic species were intercalated into the interlayer spacing of the layered compounds in order to try to reduce electrostatic interactions and also the hydrophilicity of the layers. Thus, the compatibility between the layered compounds and the polymeric matrix can be enhanced, making easier a possible exfoliation.

\subsubsection{Preparation of PLLA nanocomposites}

PLLA nanocomposites were produced by in situ intercalative ring opening polymerization using stannous octoate as catalyst. Prior to polymerization, the respective LDH ( 1 or $2 \mathrm{wt} \%$ ) was mixed with L-lactide and catalyst, using a mechanical stirrer Fisatom model 713, and this mixture was vigorously stirred at $1000 \mathrm{rpm}$ for 1 hour, at room temperature. Subsequently, the beaker containing the mixture was charged in a home-made borosilicate glass reactor, whose temperature was maintained by means of a Fisatom heating mantle model 67 . The polymerization was carried out at $120^{\circ} \mathrm{C}$ for 7 hours under dynamic flow of nitrogen. The L-lactide:catalyst molar ratio was fixed at 500:1 for all the polymerization reactions. The samples were ground using an IKAA11 grinder and passed through a 100 mesh sieve.

\subsection{Characterizations}

The X-ray diffraction measurements (XRD) were performed using a Shimadzu-XRD 7000 diffractometer, using $\mathrm{CuK}_{\alpha}$ radiation $(\lambda=1.5406 \AA)$, at a rate of $2 \% \mathrm{~min}$, operating at $40 \mathrm{KV}$ and $30 \mathrm{~mA}$, over $2 \theta$ range of $1.5-70^{\circ}$.

The transmittance of the nanocomposites was examined by a spectrophotometer Varian/Cary 5G equipment in the wavelength range of 200 to $800 \mathrm{~nm}$.

For the previous analyses, it was not necessary any sample preparation.

The FTIR spectra were obtained in a Spectrum One Perkin Elmer equipment, in a wavenumber range of 400 to $4000 \mathrm{~cm}^{-1}$, with a resolution of $4 \mathrm{~cm}^{-1}$, using $\mathrm{KBr}$ disc method.

Thermogravimetric analysis (TGA) was performed on a Universal V2.3C TA Instrument, where the samples were heated from 30 to $700^{\circ} \mathrm{C}$, with a heating rate of $20^{\circ} \mathrm{C} / \mathrm{min}$ on oxidant atmosphere (oxygen rate of $100 \mathrm{ml} / \mathrm{min}$ ).

Differential scanning calorimetric analysis (DSC) were carried out using the DSC 2910 from TA Instruments. The samples were run from 25 to $200^{\circ} \mathrm{C}$, with a heating rate of $10^{\circ} \mathrm{C} / \mathrm{min}$, held at $200^{\circ} \mathrm{C}$ for $5 \mathrm{~min}$. Then, they were cooled to $-50^{\circ} \mathrm{C}$, with a cooling rate of $30^{\circ} \mathrm{C} / \mathrm{min}$, held at $-50^{\circ} \mathrm{C}$ for $5 \mathrm{~min}$ and, after that, the samples were heated again to $200^{\circ} \mathrm{C}$ with a heating rate of $10^{\circ} \mathrm{C} / \mathrm{min}$. The cooling and heating runs were performed in a nitrogen atmosphere.

In order to carry out the mechanical tests, the samples were injection molded using a Haake Minijet injection molding system from Thermo Fisher Scientific. The injection molding 
conditions adopted were: cylinder temperature of $200^{\circ} \mathrm{C}$, injection pressure of $200 \mathrm{bar}$, injection time of 10 seconds, mold temperature of $43^{\circ} \mathrm{C}$, holding pressure of $150 \mathrm{bar}$ and a holding time of 15 seconds. The specimens had $64 \mathrm{~mm}$ in length, $12.7 \mathrm{~mm}$ in width and $3.2 \mathrm{~mm}$ in thickness.

DMA analyses were performed using a dynamic mechanical analyzer from Netzsch, type DMA 242, using the holder for three-point free bending mode. The tests were done at a frequency of $1 \mathrm{HZ}$, at a force of $1 \mathrm{~N}$ and at oscillation amplitude of 15 micrometers. The analyses were carried out at a heating rate of $5^{\circ} \mathrm{C} / \mathrm{min}$ and in the temperature range of -20 to $200^{\circ} \mathrm{C}$. The flexural properties were measured using a MTS testing machine model 810, considering a three-point loading system. The testing speed was $5 \mathrm{~mm} / \mathrm{min}$ and span length was $30 \mathrm{~mm}$.

\section{Results and Discussions}

\subsection{Layered double hydroxides}

Figures 1 and 2 show the XRD patterns, in the range of 2 theta from 1.5 to $30^{\circ}$, for the layered compounds produced. LDHs showed series of basal reflections and each of them represents a crystallographic plane present on the crystal structure of these layered compounds. The very broad basal reflections indicate a very small number of stacked layers which represent submicrometric crystal sizes. $\mathrm{Zn} / \mathrm{Cr}$ salicylate has even smaller crystals, whose XRD pattern resembles an amorphous phase.

Through XRD technique, it was possible, by using Bragg's law, to determine the basal distance of the studied layered materials, and the results are shown in Figures 1 and 2. $\mathrm{X}$-ray diffraction patterns were interpreted with respect to the position of the basal reflection (003), which corresponds to the distance between two adjacent metal hydroxide layers in the LDH 3R polymorph lattice ${ }^{[14]}$. All the LDHs synthesized exhibited basal spacing higher than the value reported in literature to hidrotalcite $(7.6 \AA)^{[14]}$ (natural LDH intercalated by carbonate anions), which is consistent with the intercalation of the organic anions. Figure 1 shows XRD patterns for the layered compounds intercalated by salicylate anions. The $\mathrm{LDHs} \mathrm{Zn} / \mathrm{Al}$ and $\mathrm{Zn} / \mathrm{Cr}$ exhibited basal spacing of $18.24 \AA$ and $17.8 \AA$, respectively.

As Brucite layer thickness is around $4.8 \hat{\mathrm{A}}^{[4]}$, these $\mathrm{LDHs}$ showed interlayer spacing of $13.44 \AA$ and $13 \AA$, respectively. Some authors ${ }^{[5]}$ reported basal spacing of $17.4 \AA$ and $15.4 \AA$ for $\mathrm{Zn} / \mathrm{Al}$ salicylate and $\mathrm{Zn} / \mathrm{Cr}$ salicylate, respectively. These differences in basal spacing can be related to different anions arrangement in the interlayer spacing. Relative to the inorganic layers, the anions can be packed in monolayer and/or bilayer, they also can be arranged perpendicularly, horizontally, or tilted at some angle and even be associated with different amounts of water. When a bilayer packing is formed, the anions can exist in an interdigitated tilted arrangement. The double layers of anions can also be tilted with an angle that can cause little or no overlap.

Figure 2 shows X-ray diffraction patterns of the LDHs(sebacate). $\mathrm{Zn} / \mathrm{Al}$ and $\mathrm{Zn} / \mathrm{Cr}$ LDHs exhibited basal spacing of $18.65 \AA$ and $17.38 \AA$, respectively. In the XRD pattern of $\mathrm{Zn} / \mathrm{Al}$, the presence of zinc sebacate is also evidenced by a peak at $12.68 \AA$ (indicated by an asterisk).

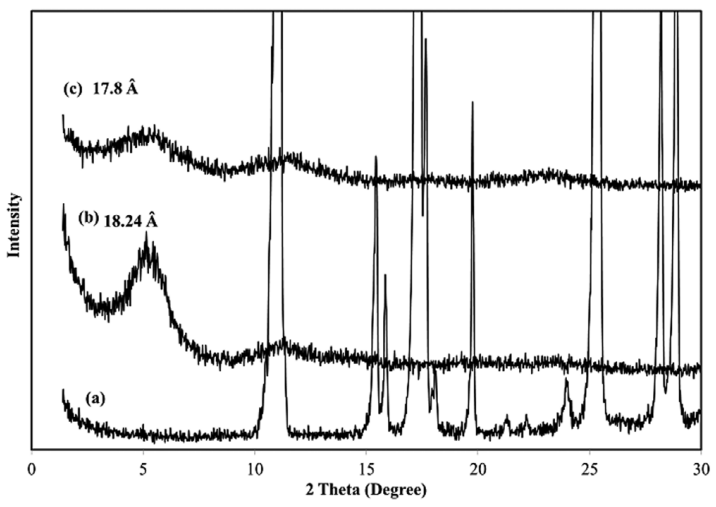

Figure 1. X-ray diffraction patterns: (a) salicylic acid, (b) $\mathrm{Zn} / \mathrm{Al}$ salicylate, (c) $\mathrm{Zn} / \mathrm{Cr}$ salicylate.



Figure 2. X-ray diffraction patterns: (a) sebacic acid, (b) $\mathrm{Zn} / \mathrm{Al}$ sebacate, (c) $\mathrm{Zn} / \mathrm{Cr}$ sebacate

The $\mathrm{Zn} / \mathrm{Cr}$ LDH exhibited broad basal peaks attributed to small crystals and basal spacing value consistent with literature data ${ }^{[16]}$. In the case of both LDHs, the basal distance is consistent with a single layer arrangement of the sebacate anions between the LDH layers.

Figure 3 shows the FTIR spectra of the LDHs studied. All the LDHs exhibited a very broad band in the range $3000-3700 \mathrm{~cm}^{-1}$. This band is LDHs characteristic and it corresponds to stretching vibration of the hydroxyl groups. LDHs(sebacate) FTIR spectra revealed bands close to $2920 \mathrm{~cm}^{-1}$ and $2850 \mathrm{~cm}^{-1}$, which can represent symmetric and asymmetric stretching vibrations of the $\mathrm{C}-\mathrm{H}$ groups, respectively. LDHs exhibited bands in the range $1590-1520 \mathrm{~cm}^{-1}$ and peaks close to $1400 \mathrm{~cm}^{-1}$, which can correspond to asymmetric and symmetric stretching vibrations of the carboxylate ion, respectively. LDHs(salicylate) revealed bands close to $1370 \mathrm{~cm}^{-1}$, which can indicate the presence of carbonate anions in the interlayer region. The band close to $1270 \mathrm{~cm}^{-1}$ and $1150 \mathrm{~cm}^{-1}$ can be associated to C-O stretching vibrations.

Figure 4 shows thermogravimetric curves (TGA) for the oxidative thermal decomposition of the intercalating anion precursors and LDHs produced. When the thermal stability of the intercalating agents was compared, it was noticed that sebacic acid exhibited the highest decomposition 


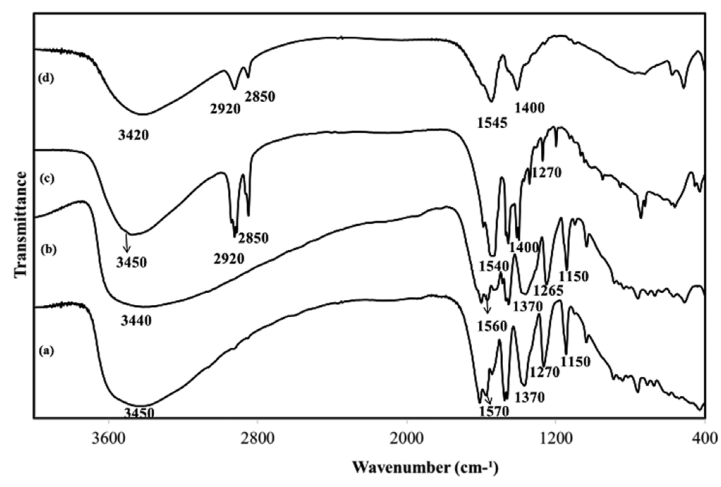

Figure 3. FTIR spectra of LDHs: (a) $\mathrm{Zn} / \mathrm{Al}$ salicylate, (b) $\mathrm{Zn} / \mathrm{Cr}$ salicylate, (c) $\mathrm{Zn} / \mathrm{Al}$ sebacate, (d) $\mathrm{Zn} / \mathrm{Cr}$ sebacate.

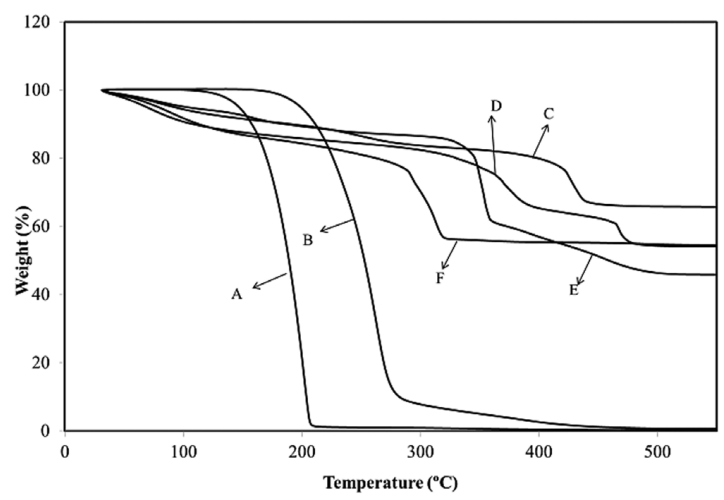

Figure 4. TGA curves to intercalating anion precursors: (A) Salicylic acid, (B) sebacic acid, and LDHs produced: (C) $\mathrm{Zn} / \mathrm{Al}$ salicylate, (D) $\mathrm{Zn} / \mathrm{Cr}$ salicylate, (E) $\mathrm{Zn} / \mathrm{Al}$ sebacate, (F) $\mathrm{Zn} / \mathrm{Cr}$ sebacate.

temperature. Sebacic acid showed a final decomposition temperature close to $450^{\circ} \mathrm{C}$. Figure 4 revealed that the acids evaluated in this study were submitted to almost complete degradation and showed less than $1 \%$ of char residues. Compared to salicylic acid, LDHs(salicylate) exhibited higher thermal stability and degradation residues. Salicylic acid sample suffered thermal decomposition until approximately $350^{\circ} \mathrm{C}$ with a char residue of $0.68 \%$, however, at $215^{\circ} \mathrm{C}$, this sample had only $1.5 \%$ of its initial weight. The thermal decomposition of $\mathrm{Zn} / \mathrm{Al}$ salicylate and $\mathrm{Zn} / \mathrm{Cr}$ salicylate occurred until $453^{\circ} \mathrm{C}$ (burning residue of $66 \%$ ) and $492^{\circ} \mathrm{C}$ (burning residue of $54 \%$ ), respectively. Sebacic acid exhibited thermal decomposition until close to $473^{\circ} \mathrm{C}$, with char residue of $0.9 \%$. $\mathrm{Zn} / \mathrm{Al}$ sebacate and $\mathrm{Zn} / \mathrm{Cr}$ sebacate suffered thermal degradation until $498^{\circ} \mathrm{C}$ (burning residue of $46 \%$ ) and $319^{\circ}$ (burning residue of $56 \%$ ), respectively.

\subsection{Polymeric nanocomposites}

Figures 5 and 6 show X-ray diffraction patterns for PLLA/(LDH salicylate) and PLLA/(LDH sebacate), respectively. PLLA revealed a strong crystalline peak close to $16.7^{\circ}$ ( 2 theta). This peak corresponds to the (200) and/or (110) plane of typical orthorhombic crystal ${ }^{[6]}$. X-ray

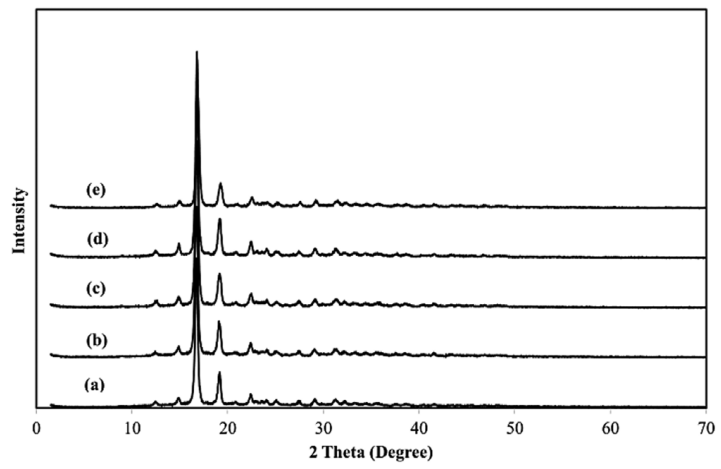

Figure 5. X-ray diffraction patterns of PLLA (a) and PLLA nanocomposites (b-e). (b) $1 \mathrm{wt} \%$ of $\mathrm{Zn} / \mathrm{Al}$ salicylate, (c) $1 \mathrm{wt} \%$ of $\mathrm{Zn} / \mathrm{Cr}$ salicylate, (d) $2 \mathrm{wt} \%$ of $\mathrm{Zn} / \mathrm{Al}$ salicylate, (e) $2 \mathrm{wt} \%$ of $\mathrm{Zn} / \mathrm{Cr}$ salicylate.

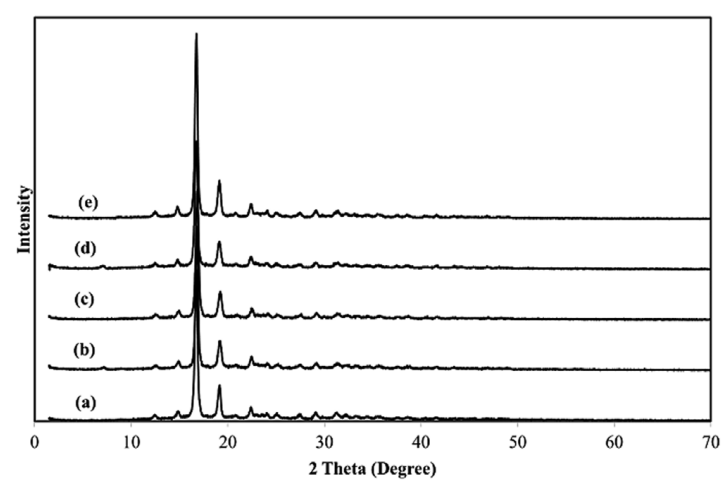

Figure 6. X-ray diffraction patterns of PLLA (a) and PLLA nanocomposites (b-e). (b) $1 \mathrm{wt} \%$ of $\mathrm{Zn} / \mathrm{Al}$ sebacate, (c) $1 \mathrm{wt} \%$ of $\mathrm{Zn} / \mathrm{Cr}$ sebacate, (d) $2 \mathrm{wt} \%$ of $\mathrm{Zn} / \mathrm{Al}$ sebacate, (e) $2 \mathrm{wt} \%$ of $\mathrm{Zn} /$ Cr sebacate.

diffraction patterns for the PLLA/(LDH sebacate) and PLLA/(LDH salicylate) exhibited a behavior very similar to that obtained for pure PLLA. This fact can indicate that, despite the LDHs presence, a similar XRD pattern is obtained. The characteristics X-ray diffractions peaks of the LDHs(sebacate) and LDHs(salicylate) were absent, which can be explained in two ways: either there was a exfoliation of the layered compounds in the polymeric matrix or the filler content is too small to be detected, the last being the most plausible one.

Figure 7 illustrates FTIR spectra of PLLA/LDHs(salicylate) nanocomposites. As FTIR spectra of PLLA/LDHs(sebacate) nanocomposites were very similar to the ones obtained for PLLA/LDHs salicylate and to avoid repetition, they will not be shown. Bands close to $3010 \mathrm{~cm}^{-1}$ and $2950 \mathrm{~cm}^{-1}$ can be attributed to $\mathrm{C}-\mathrm{H}$ stretching vibrations. The band that appears around $1760 \mathrm{~cm}^{-1}$ can be associated to $\mathrm{C}=\mathrm{O}$ stretching vibration. Bands close to $1465 \mathrm{~cm}^{-1}$ and $1388 \mathrm{~cm}^{-1}$ can correspond to $\mathrm{C}-\mathrm{H}$ asymmetric and symmetric bending vibrations, respectively. Bands close to $1182 \mathrm{~cm}^{-1}$ and $1090 \mathrm{~cm}^{-1}$ can be related to $\mathrm{C}-\mathrm{O}$ stretching vibrations. Two bands related to the crystalline and amorphous phases 
of PLA were found at $871 \mathrm{~cm}^{-1}$ and $756 \mathrm{~cm}^{-1}$. The band at $871 \mathrm{~cm}^{-1}$ can be assigned to the amorphous phase and the band at $756 \mathrm{~cm}^{-1}$ to the crystalline phase $\mathrm{e}^{[17]}$. Bands close to $1220 \mathrm{~cm}^{-1}$ can be associated to C-O asymmetric stretching vibrations, characteristics of PLLA spectra.

Figures 8 and 9 show visible and ultraviolet transmission spectra of PLLA and PLLA nanocomposites. The ultraviolet and visible light transmission is one of the main factors that should be evaluated in polymers used for food packaging applications, in order to select materials that can preserve the foods quality until the moment of their consumption. Sensitive components of foods such as lipids, flavors, vitamins, and pigments may undergo degradation reactions when exposed to light ${ }^{[18]}$. The main driver is the need for extending the shelf-life and reducing the damages of the foods. This way, besides the suitable selection of the materials for the production of food packaging, it is also important to verify other strategies to increase polymers light barrier properties, like the incorporation of additives and/or light absorbers. Ultraviolet light and visible spectrum range from 100-400 $\mathrm{nm}$ and from 400-700 nm, respectively.

PLLA exhibited an increase in the UV light transmission at $234 \mathrm{~nm}$ and, at $318 \mathrm{~nm}$, this polymer showed the highest light transmittance $(95 \%)$. In the visible region, PLLA transmittance ranged from $73 \%$ to $83 \%$. The transparency

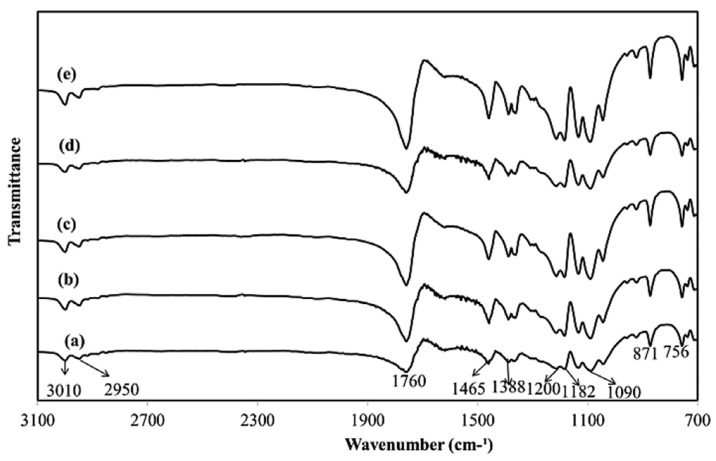

Figure 7. FTIR spectra of PLLA (a) and PLLA nanocomposites (b-e). (b) $1 \mathrm{wt} \%$ of $\mathrm{Zn} / \mathrm{Al}$ salicylate, (c) $2 \mathrm{wt} \%$ of $\mathrm{Zn} / \mathrm{Al}$ salicylate, (d) $1 \mathrm{wt} \%$ of $\mathrm{Zn} / \mathrm{Cr}$ salicylate, (e) $2 \mathrm{wt} \%$ of $\mathrm{Zn} / \mathrm{Cr}$ salicylate.



Figure 8. Percent transmission versus wavelength for PLLA and PLLA/LDH(salicylate) nanocomposites. of plastic sheeting is defined as the transmission of visible light on the range $540-560 \mathrm{~nm}^{[17]}$. In the present study, PLLA transmitted, in this range, $78 \%$ of the light. Figure 8 revealed that almost all the LDHs(salicylate) nanocomposites transmitted less UVB and UVA light than PLLA. The nanocomposite containing $1 \mathrm{wt} \%$ of $\mathrm{Zn} / \mathrm{Al}$ salicylate exhibited, on the range 540-560 nm, a PLLA similar light transmission (78\%). This nanocomposite showed, at UVA and UVB wavelength region, transmittances that ranged from 51 to $81 \%$ and from 63 to $82 \%$, respectively. PLLA exhibited, at UVA and UVB wavelength region, transmittances that ranged from 83 to $94 \%$ and from 76 to $93 \%$, respectively. Compared to PLLA, the nanocomposite containing $1 \mathrm{wt} \%$ of $\mathrm{Zn} / \mathrm{Al}$ salicylate transmitted less UVA and UVB light and exhibited a similar transparency. Figure 9 shows ultraviolet and visible transmission spectra of the PLLA/(LDHs/sebacate) nanocomposites. Nanocomposites light transmission spectra behavior was similar to PLLA, in the entire studied wavelength. Compared to PLLA, the nanocomposites containing $\mathrm{Zn} / \mathrm{Cr}$ sebacate transmitted less UVA, UVB and visible light. These nanocomposites showed transmittances close to $55 \%$, in the range 540-560 $\mathrm{nm}$.

The results demonstrated that the addition of $1 \mathrm{wt} \%$ of $\mathrm{Zn} / \mathrm{Al}$ salicylate in the PLLA composition can reduce the polymer transmission in the UVA and UVB wavelength region, while keeping a similar PLLA transparency. By means of these results it can be noticed that the correct selection of layered compounds can affect the PLLA light transmission.

Table 1 summarizes the main results of the oxidative thermal decomposition processes of PLLA and PLLA nanocomposites. It can be noticed that all the nanocomposites showed a $\mathrm{T}_{10}$ (temperature at which $10 \%$ of mass loss occurs) lower than PLLA. According to some authors ${ }^{[19]}$ the thermal decomposition of PLLA occurs by random chain scission or specific chain-end scission, because the aliphatic ester structure is relatively easy to hydrolyze and break down. The impurities and/or the organic molecule, which have been used to modify the filler, first decompose, which provokes the subsequent thermal decomposition of PLLA. At 50\% weight loss $\left(\mathrm{T}_{50}\right)$, compared to PLLA, the nanocomposites containing 1 and $2 \mathrm{wt} \%$ of $\mathrm{Zn} / \mathrm{Al}$ salicylate, revealed a slight increase on decomposition temperatures. These same nanocomposites exhibited, at $90 \%$ weight loss $\left(\mathrm{T}_{90}\right)$, a small

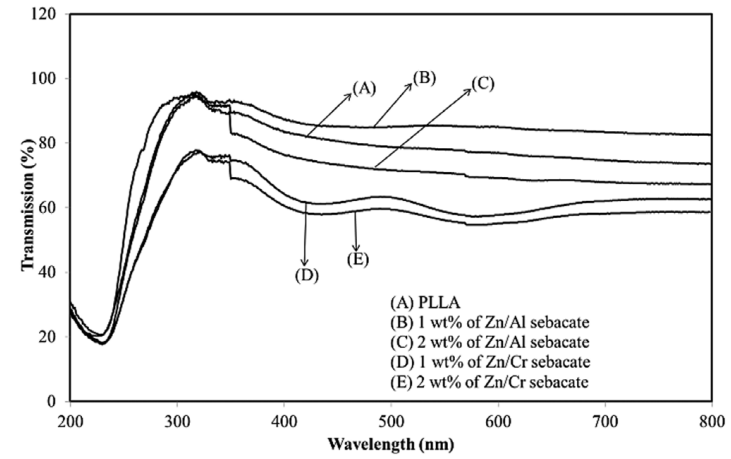

Figure 9. Percent transmission versus wavelength for PLLA and PLLA/LDH(sebacate) nanocomposites. 
Table 1. Temperatures for the thermal degradation of PLLA and PLLA nanocomposites.

\begin{tabular}{cccc}
\hline Sample & $\mathbf{T}_{\mathbf{1 0}}\left({ }^{\circ} \mathbf{C}\right)$ & $\mathbf{T}_{\mathbf{5 0}}\left({ }^{\circ} \mathbf{C}\right)$ & $\mathbf{T}_{\mathbf{9 0}}\left({ }^{\circ} \mathbf{C}\right)$ \\
\hline PLLA & 246 & 277 & 294 \\
PLLA $/(1 \mathrm{wt} \%$ of $Z \mathrm{n} / \mathrm{Al}$ salicylate $)$ & 245 & 282 & 302 \\
PLLA $/(2 \mathrm{wt} \%$ of $\mathrm{Zn} / \mathrm{Al}$ salicylate $)$ & 239 & 279 & 299 \\
PLLA $/(1 \mathrm{wt} \%$ of $\mathrm{Zn} / \mathrm{Cr}$ salicylate $)$ & 235 & 269 & 284 \\
PLLA $/(2 \mathrm{wt} \%$ of $\mathrm{Zn} / \mathrm{Cr}$ salicylate $)$ & 234 & 270 & 290 \\
PLLA $/(1 \mathrm{wt} \%$ of $\mathrm{Zn} / \mathrm{Al}$ sebacate) & 234 & 272 & 295 \\
PLLA $/(2 \mathrm{wt} \%$ of $\mathrm{Zn} / \mathrm{Al}$ sebacate $)$ & 232 & 272 & 294 \\
PLLA $/(1 \mathrm{wt} \%$ of $\mathrm{Zn} / \mathrm{Cr}$ sebacate $)$ & 236 & 270 & 289 \\
PLLA $/(2 \mathrm{wt} \%$ of $\mathrm{Zn} / \mathrm{Cr}$ sebacate $)$ & 234 & 272 & 291 \\
\hline
\end{tabular}

increase on thermal stability, compared to PLLA. These results demonstrated that, at higher temperatures, some inorganic filler were more able prevent the thermal decomposition of PLLA. This fact can be attributed to shielding effect of layer of these LDHs to the evolution of produced products during the later stage of decomposition ${ }^{[19]}$, improving the thermal stability.

Figure 10 and 11 show the storage modulus and loss modulus as a function of the temperature for PLLA salicylate and PLLA sebacate nanocomposites, respectively. Figure 10 displays that, with the exception of the nanocomposite containing $2 \mathrm{wt} \%$ of $\mathrm{Zn} / \mathrm{Cr}$ salycilate, all other nanocomposites exhibited storage modulus values very close to the ones found for PLLA. On the other hand, all the nanocomposites containing LDH sebacate in their composition showed lower elastic modulus than PLLA. The decrease in storage modulus may be caused by some agglomerated LDH platelets in the PLLA matrix that act as sites of stress concentration ${ }^{[5]}$.

It was not possible to evaluate the dynamic mechanical properties of the nanocomposite containing $2 \mathrm{wt} \%$ of $\mathrm{Zn} / \mathrm{Al}$ salicylate, because these samples were fractured at the beginning of the tests.

The glass transition temperature $\left(\mathrm{T}_{\mathrm{g}}\right)$ can be obtained through the peak of the curve of loss modulus as a function of the temperature. The values of $\mathrm{T}_{\mathrm{g}}$ for PLLA and the nancomposites containing $1 \mathrm{wt} \%$ of $\mathrm{Zn} / \mathrm{Al}$ salicylate, $1 \mathrm{wt} \%$ of $\mathrm{Zn} / \mathrm{Cr}$ salicylate and $2 \mathrm{wt} \%$ of $\mathrm{Zn} / \mathrm{Cr}$ salicylate, were of $61.7^{\circ} \mathrm{C}, 67.6^{\circ} \mathrm{C}, 62.3^{\circ} \mathrm{C}$ and $62^{\circ} \mathrm{C}$, respectively. The nanocomposites containing $1 \mathrm{wt} \%$ of $\mathrm{Zn} / \mathrm{Al}$ sebacate, $2 \mathrm{wt} \%$ of $\mathrm{Zn} / \mathrm{Al}$ sebacate, $1 \mathrm{wt} \%$ of $\mathrm{Zn} / \mathrm{Cr}$ salicylate and $2 \mathrm{wt} \%$ of $\mathrm{Zn} / \mathrm{Cr}$ salicylate exhibited $\mathrm{T}_{\mathrm{g}}$ values of $66.8^{\circ} \mathrm{C}$, $63.1^{\circ} \mathrm{C}, 68.4^{\circ} \mathrm{C}$ and $68^{\circ} \mathrm{C}$, respectively. The results displayed that, compared to PLLA, all the nanocomposites exhibited higher $T_{g}$ values. These results can be attributed to physical and/or chemical interactions that may arise between the filler and the polymer ${ }^{[20]}$, these interactions could reduce the available free volume, and thus the chains mobility.

At temperatures close to $50^{\circ} \mathrm{C}$, the storage modulus and loss modulus were high and low, respectively, and the samples acted as a glassy material, and thus, stiff ${ }^{211}$. At temperatures above $80^{\circ} \mathrm{C}$, both the modulus were low, and the samples exhibited a viscous behavior. When the storage modulus decreases with the increase of the temperature and the loss modulus exhibits a maximum, the viscoelastic behavior is reached.

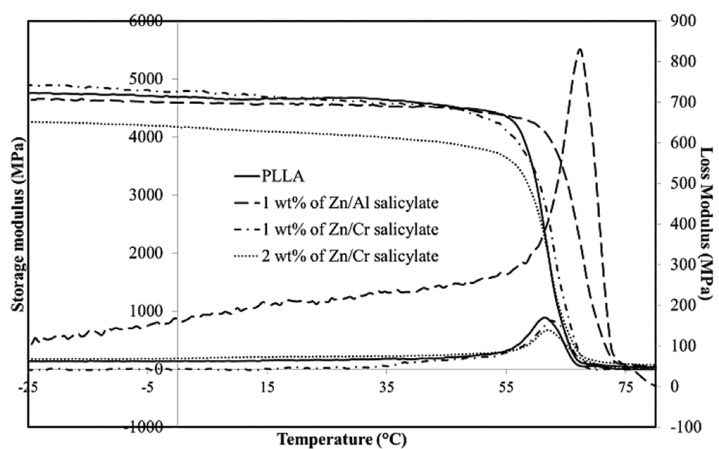

Figure 10. Storage modulus and loss modulus as a function of the temperature for PLLA and PLLA/(LDH salicylate) nanocomposites.

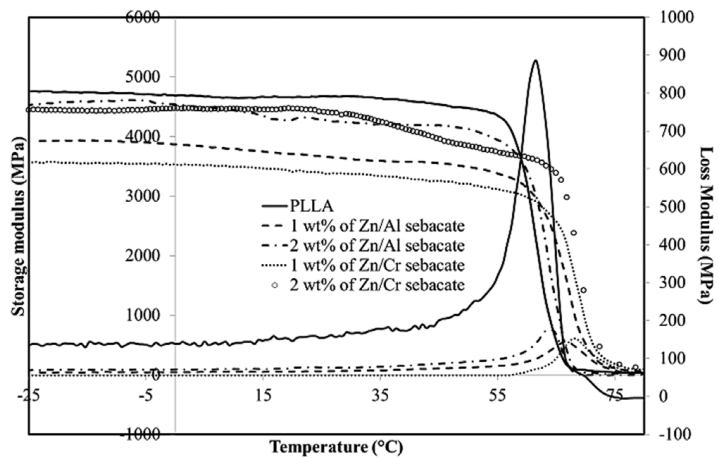

Figure 11. Storage modulus and loss modulus as a function of the temperature for PLLA and PLLA/(LDH sebacate) nanocomposites.

Table 2 displays a summary of the main parameters (modulus of elasticity, maximum bending stress and elongation at break point) obtained from flexural test. The modulus of elasticity is a parameter that expresses the stiffness of a material, at the beginning of the flexural test. Through Table 2 , it can be noticed that all the studied nanocomposites exhibited lower modulus of elasticity than PLLA and, as the reinforcement agent concentration increased, the modulus of elasticity decreased, for most of the samples.

In thermoplastic-based (intercalated or exfoliated) nanocomposites, the stress at break, which expresses the 
ultimate strength that the material can bear before break, may vary strongly depending on the nature of the interactions between the matrix and the filler ${ }^{[3]}$.

All the nanocomposites exhibited lower stress at break values than PLLA. These results can indicate that weak interfacial interactions between the polymer and the fillers took place. If a strong interface between the reinforcement agent and the polymer occurs, when a load is applied, it is efficiently transferred from surface to the entire polymeric matrix, by means of this interface, enhancing the mechanical properties of the nanocomposite. On the other hand, when a weak interface is present, the load distribution become less efficient, and the mechanical properties exhibit no improvement or they are negatively affected.

PLLA and the nanocomposites exhibited stress versus strain curves qualitatively similar. In these cases, the post-peak curves go down very rapidly almost in a straight line without increasing in strains. This indicates that the specimen breaks into two pieces when the maximum stress is reached ${ }^{[22]}$.

Through Table 2, it can be seen that all the samples showed lower elongation at break values than PLLA. It can also be noticed that, for most of the nanocomposites, an increase in the filler concentrations caused a decrease in the strain at break values.

Table 3 summarizes the main results obtained by differential scanning calorimetry (DSC) (glass transition temperature, melting temperature, cold crystallization temperature, cold crystallization enthalpy, melting enthalpy, percent crystallinity, melt crystallization temperature, melt crystallization enthalpy). In the present study, firstly, the samples were heated from $25^{\circ} \mathrm{C}$ to $200^{\circ} \mathrm{C}$, held at this temperature for five minutes, in order to extinguish their thermal history. As pure PLLA and all the nanocomposites displayed both thermal transitions (glass transition temperature and melting temperature) they can be classified as semicrystalline materials.

The degree of crystallinity of the samples was calculated according to the following Equation 1:

$$
X_{c}=\frac{\Delta H_{m}}{(1-\varphi) \Delta H_{m}^{0}} * 100
$$

Where: $X_{c}$ is the percent crystallinity, $\Delta H_{m}$ is the melt enthalpy of the studied material, $\varphi$ is the fraction of filler in the sample, $\Delta H_{m}$ is the melt enthalpy of $100 \%$ crystalline PLLA that was taken as $93 \mathrm{~J} / \mathrm{g}^{[12]}$.

Through Table 3, it can be noticed that all the samples exhibited lower glass transition temperatures than PLLA. According to some authors ${ }^{[8]}$ this decrease could have been due to the plasticizing effect of the anions, which were used in the intercalation of the fillers.

In this study, it was possible to obtain the crystallization temperature from molten samples $\left(\mathrm{T}_{\mathrm{mc}}\right)$ (during the cooling scans) and from cold samples $\left(\mathrm{T}_{\mathrm{cc}}\right)$ (during the heating scans). During the second heating scan, the nanocomposites containing $1 \mathrm{wt} \%$ of $\mathrm{Zn} / \mathrm{Al}$ sebacate and $1 \mathrm{wt} \%$ of $\mathrm{Zn} / \mathrm{Cr}$

Table 2. Summary of the some parameters obtained from flexure test.

\begin{tabular}{cccc}
\hline & Modulus of elasticity (MPa) & Stress at break (MPa) & Elongation at break (\%) \\
\hline PLLA & $3815+/-147.9$ & $20.6+/-4.16$ & $0.54+/-0.09$ \\
PLLA/(1 wt $\% \mathrm{Zn} / \mathrm{Al}$ salicylate) & $3588+/-20.9$ & $11.7+/-1.97$ & $0.33+/-0.05$ \\
PLLA/(2 wt $\% \mathrm{Zn} / \mathrm{Al}$ salicylate) & $3434+/-411.1$ & $5.8+/-0.25$ & $0.17+/-0.015$ \\
PLLA/(1 wt $\% \mathrm{Zn} / \mathrm{Cr}$ salicylate) & $2965+/-187.8$ & $8.5+/-0.73$ & $0.28+/-0.039$ \\
PLLA/(2 wt $\% \mathrm{Zn} / \mathrm{Cr}$ salicylate) & $3158+/-191.1$ & $6.7+/-1.39$ & $0.21+/-0.033$ \\
PLLA $/(1 \mathrm{wt} \% \mathrm{Zn} / \mathrm{Al}$ sebacate) & $3513+/-429.7$ & $13.6+/-2.28$ & $0.39+/-0.02$ \\
PLLA/(2 wt $\% \mathrm{Zn} / \mathrm{Al}$ sebacate) & $3266+/-123.3$ & $7.1+/-0.47$ & $0.22+/-0.007$ \\
PLLA $/(1 \mathrm{wt} \% \mathrm{Zn} / \mathrm{Cr}$ sebacate) & $3420+/-269.5$ & $10.7+/-2.78$ & $0.3+/-0.062$ \\
PLLA $/(2 \mathrm{wt} \% \mathrm{Zn} / \mathrm{Cr}$ sebacate) & $3018+/-202.6$ & $6.1+/-0.96$ & $0.2+/-0.019$ \\
\hline
\end{tabular}

Table 3. Glass transition temperature $\left(\mathrm{T}_{\mathrm{g}}\right)$, cold crystallization temperature $\left(\mathrm{T}_{\mathrm{cc}}\right)$, cold crystallization enthalpy $\left(\Delta \mathrm{H}_{\mathrm{cc}}\right)$, melting temperature $\left(\mathrm{T}_{\mathrm{m}}\right)$, melting enthalpy $\left(\Delta \mathrm{H}_{\mathrm{m}}\right)$ percent crystallinity $\left(\mathrm{X}_{\mathrm{c}}\right)$, melt crystallization temperature $\left(\mathrm{T}_{\mathrm{mc}}\right)$, melt crystallization enthalpy $\left(\Delta \mathrm{H}_{\mathrm{mc}}\right)$ for PLLA and the PLLA nanocomposites.

\begin{tabular}{|c|c|c|c|c|c|c|c|c|}
\hline & $\begin{array}{c}\mathrm{T}_{\mathrm{g}}\left({ }^{\circ} \mathrm{C}\right) \\
\left(+/-\mathbf{0 .} 1^{\circ} \mathrm{C}\right) \\
2^{\circ} \text { heating } \\
\text { scan }\end{array}$ & $\begin{array}{c}\mathrm{T}_{\mathrm{cc}}\left({ }^{\circ} \mathrm{C}\right) \\
\left(+/-0.1^{\circ} \mathrm{C}\right) \\
2^{\circ} \text { heating } \\
\text { scan }\end{array}$ & $\begin{array}{c}\Delta H_{\mathrm{cc}}(\mathrm{J} / \mathrm{g}) \\
(+/-1 \%) \\
2^{\circ} \text { heating } \\
\text { scan }\end{array}$ & $\begin{array}{c}\mathbf{T}_{m}\left({ }^{\circ} \mathrm{C}\right) \\
\left(+/-0.1^{\circ} \mathrm{C}\right) \\
2^{\circ} \text { heating } \\
\text { scan }\end{array}$ & $\begin{array}{c}\Delta H_{m}(J / g) \\
(+/-1 \%) \\
2^{\circ} \text { heating } \\
\text { scan }\end{array}$ & $X_{c}(\%)$ & $\begin{array}{c}\mathrm{T}_{\mathrm{mc}}\left({ }^{\circ} \mathrm{C}\right) \\
\left(+/-0.1^{\circ} \mathrm{C}\right) \\
\text { Cooling scan }\end{array}$ & $\begin{array}{c}\Delta \mathbf{H}_{\mathrm{mc}} \\
(+/-1 \%) \\
(\mathrm{J} / \mathrm{g}) \\
\text { Cooling scan }\end{array}$ \\
\hline PLLA & 54.3 & 91.7 & 28.6 & 170.2 & 81.2 & 87.3 & 94 & 27.2 \\
\hline $1 \mathrm{wt} \%$ of $\mathrm{Zn} / \mathrm{Al}$ salicylate & 49 & 94.8 & 42.4 & 164.7 & 79.8 & 86.7 & 87 & 14.46 \\
\hline $2 \mathrm{wt} \%$ of $\mathrm{Zn} / \mathrm{Al}$ salicylate & 48.6 & 91.4 & 40.8 & 163 & 73.1 & 80.2 & 81.3 & 10.41 \\
\hline $1 \mathrm{wt} \%$ of $\mathrm{Zn} / \mathrm{Cr}$ salicylate & 49.6 & 94.5 & 48 & 165.2 & 76.6 & 83.1 & 83 & 7 \\
\hline $2 \mathrm{wt} \%$ of $\mathrm{Zn} / \mathrm{Cr}$ salicylate & 47.9 & 88.1 & 53.5 & 162.2 & 74.1 & 81.3 & 80 & 3.8 \\
\hline $1 \mathrm{wt} \%$ of $\mathrm{Zn} / \mathrm{Al}$ sebacate & 39 & 86.1 & 4.1 & 158.1 & 83.2 & 90.3 & 100.9 & 59.17 \\
\hline $2 \mathrm{wt} \%$ of $\mathrm{Zn} / \mathrm{Al}$ sebacate & 46.9 & 92.6 & 47.5 & 165.3 & 71 & 77.9 & 82.5 & 5.6 \\
\hline $1 \mathrm{wt} \%$ of $\mathrm{Zn} / \mathrm{Cr}$ sebacate & 52.6 & 97.9 & 51.6 & 168.8 & 83.6 & 90.8 & 87.8 & 5.8 \\
\hline $2 \mathrm{wt} \%$ of $\mathrm{Zn} / \mathrm{Cr}$ sebacate & 50.6 & 92.2 & 50.6 & 165.4 & 82.4 & 90.5 & 85.9 & 5.3 \\
\hline
\end{tabular}


sebacate showed, respectively, the lowest and the highest crystallization temperatures. For other hand, during the cooling scan, the nanocomposites containing $2 \mathrm{wt} \%$ of $\mathrm{Zn} / \mathrm{Cr}$ salycilate and $1 \mathrm{wt} \%$ of $\mathrm{Zn} / \mathrm{Al}$ sebacate exhibited, respectively, the lowest and the highest crystallization temperatures. According to some authors ${ }^{[8]}$ usually, a lower $\mathrm{T}_{c c}$ indicates faster crystallization, whereas a lower $\mathrm{T}_{\mathrm{mc}}$ indicates slower crystallization. Therefore, the decrease in $T_{c c}$ coupled with the increase in $T_{m c}$ could have been an indicator of a crystallization-promoting effect of the nanofiller. The nanocomposite containing $1 \mathrm{wt} \%$ of $\mathrm{Zn} / \mathrm{Al}$ sebacate exhibited the above-mentioned conditions. This is may be to an increase in the interaction between these filler particles and the matrix, improving the nucleating activity of the filler and promoting faster crystallization ${ }^{[23]}$.

Table 3 shows that all the nanocomposites exhibited lower melting temperatures than PLLA. This finding might be due to variations in the molecular weight of PLA since it is known that the PLA melting point is influenced by polymer chain length ${ }^{[12]}$. Some authors ${ }^{[1,10,12]}$ reported the decrease in molecular weights of PLLA nanocomposites containing LDHs. This reduction in molecular weight could arise due to release of tightly bound water in the LDH interlayer spacing which would cause hydrolytic degradation of PLA chains. However the role of metal centers in the LDH or hydroxyl groups on the LDH surfaces as sites for catalysis of degradation cannot be disconsidered ${ }^{[12]}$.

After analyzing the data of melting enthalpy, it was noticed that, compared to PLLA $\left(\Delta \mathrm{H}_{\mathrm{m}}=81.2 \mathrm{~J} / \mathrm{g}\right)$, only the nanocomposites containing $1 \mathrm{wt} \%$ of $\mathrm{Zn} / \mathrm{Al}$ sebacate $\left(\Delta \mathrm{H}_{\mathrm{m}}=83.2 \mathrm{~J} / \mathrm{g}\right), 1 \mathrm{wt} \%$ of $\mathrm{Zn} / \mathrm{Cr}$ sebacate $\left(\Delta \mathrm{H}_{\mathrm{m}}=83.6 \mathrm{~J} / \mathrm{g}\right)$ and $2 \mathrm{wt} \%$ of $\mathrm{Zn} / \mathrm{Cr}$ sebacate $\left(\Delta \mathrm{H}_{\mathrm{m}}=82.4 \mathrm{~J} / \mathrm{g}\right)$ displayed a little increase of this parameter.

The nanocomposite containing $1 \mathrm{wt} \%$ of $\mathrm{Zn} / \mathrm{Cr}$ sebacate showed the highest percent crystallinity value. For other hand, the lowest value of this parameter was found for the nanocomposite containing $2 \mathrm{wt} \%$ of $\mathrm{Zn} / \mathrm{Al}$ sebacate. These observations can indicate that some fillers exhibited, at certain concentrations, higher nucleation tendencies, giving rise to more uniform crystal sizes ${ }^{[1]}$.

\section{Conclusions}

An experimental study about in situ bulk polymerization of L-Lactide filled by layered double hydroxides was carried out. It was noticed that the nanocomposite containing $1 \mathrm{wt} \%$ of $\mathrm{Zn} / \mathrm{Al}$ salicylate exhibited the lowest transmittance in the UVA and UVB range, while keeping a transparence similar to PLLA. TGA results showed that it was possible to obtain a little increase in the decomposition temperature of the PLLA $\left(8^{\circ} \mathrm{C}\right)$ by means of the addition of $1 \mathrm{wt} \%$ of $\mathrm{Zn} / \mathrm{Al}$ salicylate. Results of flexural test showed that all the nanocomposites presented lower stress at break and elongation at break values than PLLA. DSC results demonstrated that, compared to PLLA, all the nanocomposites displayed decreases on glass transition temperatures as well as on melting temperatures.

\section{Acknowledgements}

The authors would like to acknowledge the financial support from Fapesp (Fundação de amparo a pesquisa do Estado de São Paulo) [Foundation for Research Support of the State of São Paulo] and Capes (Coordenação de aperfeiçoamento de pessoal de nível superior) [Coordination for the Improvement of Higher Education Personel].

\section{References}

1. Katiyar, V., Gerds, N., Koch, C., Risbo, J., Hansen, H., \& Plackett, D. (2011). Melt processing of poly(L-lactic acid) in the presence of organomodified anionic or cationic clays. Journal of Applied Polymer Science, 122(1), 112-125. http:// dx.doi.org/10.1002/app.33984.

2. Mahboobeh, E., Yunus, W., Hussein, Z., Ahmad, M., \& Ibrahim, N. (2010). Flexibility improvement of poly(lactic acid) by stearate-modified layered double hydroxide. Journal of Applied Polymer Science, 118(2), 1077-1083. http://dx.doi. org/10.1002/app.32461

3. Alexandre, M., \& Dubois, P. (2000). Polymer-layered silicate nanocomposites: preparation, properties and uses of a new class of materials. Materials Science and Engineering, 28(1-2), 1-63. http://dx.doi.org/10.1016/S0927-796X(00)00012-7.

4. Wypych, F., Arizaga, G. G. C., \& Satyanarayana, K. G. (2008). Synthetic layered materials/ polymer nanocomposites. In S. Thomas \& G. Zaikov (Eds.). Polymer nanocomposite research advances (pp. 95-143). New York: Nova Science Publishers.

5. Chiang, M., \& Wu, T. (2012). Preparation and characterization of melt processed poly(L-lactide)/layered double hydroxide nanocomposites. Composites. Part B, Engineering, 43(7), 2789 2794. http://dx.doi.org/10.1016/j.compositesb.2012.04.040.

6. Chiang, M., Chu, M., \& Wu, T. (2011). Effect of layered double hydroxides on the thermal degradation behavior of biodegradable poly(L-lactide) nanocomposites. Polymer Degradation \& Stability, 96(1), 60-66. http://dx.doi.org/10.1016/j. polymdegradstab.2010.11.002.

7. Chiang, M., \& Wu, T. (2010). Synthesis and characterization of biodegradable poly(L-lactide)/layered double hydroxide nanocomposites. Composites Science and Technology, 70(1), 110-115. http://dx.doi.org/10.1016/j.compscitech.2009.09.012.

8. Dagnon, K., Ambadapadi, S., Shaito, A., Ogbomo, S., DeLeon, V., Golden, T., Rahimi, M., Nguyen, K., Braterman, P., \& D'Souza, N. (2009). Poly(L-lactic acid) nanocomposites with layered double hydroxides functionalized with ibuprofen. Journal of Applied Polymer Science, 113(3), 1905-1915. http:// dx.doi.org/10.1002/app.30159.

9. Ha, J., \& Xanthos, M. (2010). Novel modifiers for layered double hydroxides and their effects on the properties of polylactic acid composites. Applied Clay Science, 47(3-4), 303-310. http://dx.doi.org/10.1016/j.clay.2009.11.033.

10. Gerds, N., Katiyar, V., Koch, C., Hansen, H., Plackett, D., Larsen, E., \& Risbo, J. (2012). Degradation of L-polylactide during melt processing with layered double hydroxides. Polymer Degradation \& Stability, 97(10), 2002-2009. http:// dx.doi.org/10.1016/j.polymdegradstab.2012.04.014.

11. Wang, D., Leuteritz, A., Wang, Y., Wagenknecht, U., \& Heinrich, G. (2010). Preparation and burning behaviors of flame retarding biodegradable poly(lactic acid) nanocomposite based on zinc aluminum layered double hydroxide. Polymer Degradation \& Stability, 95(12), 2474-2480. http://dx.doi.org/10.1016/j. polymdegradstab.2010.08.007.

12. Katiyar, V., Gerds, N., Koch, C., Risbo, J., Hansen, H., \& Plackett, D. (2010). Poly L-lactide-layered double hydroxide nanocomposites via in situ polymerization of L-lactide. Polymer Degradation \& Stability, 95(12), 2563-2573. http://dx.doi. org/10.1016/j.polymdegradstab.2010.07.031. 
13. Arizaga, G., Satyanarayana, K., \& Wypych, F. (2007). Layered hydroxide salts: synthesis, properties and potential applications. Solid State Ionics, 178(15-18), 1143-1162. http:// dx.doi.org/10.1016/j.ssi.2007.04.016.

14. Costa, F., Leuteritz, A., Wagenknecht, U., Jehnichen, D., Haubler, L., \& Heinrich, G. (2008). Intercalation of Mg-Al layered double hydroxide by anionic surfactants: preparation and characterization. Applied Clay Science, 38(3-4), 153-164. http://dx.doi.org/10.1016/j.clay.2007.03.006.

15. Meyn, M., Beneke, K., \& Lagaly, G. (1990). Anion-exchange reactions of layered double hydroxides. Inorganic Chemistry, 29(26), 5201-5207. http://dx.doi.org/10.1021/ic00351a013.

16. Pang, X., Ma, X., Li, D., \& How, W. (2013). Synthesis and characterization of 10-hydroxycamptothecin-sebacate-layered double hydroxide nanocomposites. Solid State Sciences, 16, 7175. http://dx.doi.org/10.1016/j.solidstatesciences.2012.10.008.

17. Auras, R., Harte, B., \& Selke, S. (2004). An overview of polylactides as packaging materials. Macromolecular Bioscience, 4(9), 835-864. http://dx.doi.org/10.1002/mabi.200400043. PMid: 15468294.

18. Auras, R., Lim, L., Selke, S. E. M., \& Tsuji, H. (2010). Poly(lactic acid) synthesis, structures, properties, processing, and applications. New Jersey: John Wiley \& Sons. http:// dx.doi.org/10.1002/9780470649848.

19. Chen, H., Chen, J., Shao, L., Yang, J., Huang, T., Zhang, N., \& Wang, Y. (2013). Comparative study of poly(L-lactide) nanocomposites with organic montmorillonite and carbon nanotubes. Journal of Polymer Science. Part B, Polymer Physics, 51(3), 183-196. http://dx.doi.org/10.1002/polb.23182.

20. Nogueira, T., Botan, R., Neto, J., Wypych, F., \& Lona, L. (2013). Effect of layered double hydroxide, on the mechanical, termal, and fire properties of poly(methyl methacrylate) nanocomposites. Advances in Polymer Technology, 32(S1), E660-E674. http://dx.doi.org/10.1002/adv21309.

21. Cassu, S., \& Felisberti, M. (2005). Comportamento dinâmicomecânico e relaxações em polímeros e blendas poliméricas. Quimica Nova, 28(2), 255-263. http://dx.doi.org/10.1590/ S0100-40422005000200017.

22. Yan, L., Chouw, N., \& Yuan, X. (2012). Improving the mechanical properties of natural fibre fabric reinforced epoxy composites by alkali treatment. Journal of Reinforced Plastics and Composites, 31(6), 425-437. http://dx.doi.org/10.1177/0731684412439494.

23. Oiu, W., Mai, K., \& Zeng, H. (2000). Effect of silanegrafted polypropylene on the mechanical properties and crystallization behavior of talc/polypropylene composites. Journal of Applied Polymer Science, 77(13), 2974-2977. http:// dx.doi.org/10.1002/1097-4628(20000923)77:13<2974::AIDAPP22>3.0.CO;2-R.

Received: July 07, 2015

Revised: Sept. 09, 2015 Accepted: Sept. 21, 2015 